\title{
PERANCANGAN MULTIMEDIA INTERAKTIF PENGENALAN DKV MA CHUNG SEBAGAI UPAYA MENINGKATKAN BRAND EQUITY
}

\author{
Sultan Arif Rahmadianto ${ }^{1}$, Melany ${ }^{2}$ \\ ${ }^{1}$ Program Studi Desain Komunikasi Visual, Fakultas Sains dan Teknologi, Universitas Ma Chung \\ 2 Program Studi Sastra Inggris, Fakultas Bahasa dan Seni, Universitas Ma Chung \\ sultan.arif@machung.ac.id ${ }^{1}$, melany.agustina@machung.ac.id ${ }^{2}$
}

\begin{abstract}
Abstrak
Program studi Desain Komunikasi Visual (DKV) di Malang memiliki banyak peminat dan terus meningkat. Zaman sekarang sudah banyak perguruan tinggi swasta yang membuka program studi DKV tidak terkecuali Universitas Ma Chung. Program studi S1 DKV Universitas Ma Chung atau lebih dikenal dengan DKV Ma Chung yang terletak di Malang ini merupakan program studi tergolong masih baru dan belum memiliki lulusan. Perkembangan suatu program studi di perguruan tinggi swasta sangat bergantung pada jumlah mahasiswa. Untuk memiliki peminat mahasiswa yang tinggi diantara peguruan tinggi swasta lain, program studi DKV Ma Chung harus memiliki brand equity. Multimedia interaktif adalah sebuah media yang mampu menyampaian informasi lebih kreatif, inovatif dan efektif. Maka dari itu tujuan penelitian ini adalah merancang multimedia interaktif pengenalan DKV Ma Chung sebagai upaya meningkatkan brand equity. Metode perancangan multimedia interaktif menggunakan pendekatan kualitatif proses desain ADDIE meliputi Analysis, Design, Development, Implementation, dan Evaluation. Metode ADDIE adalah model instruksi desain dengan sebuah framework yang membantu perancangan media. Manfaat jangka panjang dari penelitian ini adalah meningkatkan jumlah mahasiswa program studi DKV Ma Chung yang sangat penting bagi perkembangan sebuah program studi.
\end{abstract}

Kata Kunci: DKV Ma Chung, brand equity, ADDIE, dan multimedia interaktif.

\begin{abstract}
Recently, the number of applicants to study visual communication design in Malang increased significantly. The fact that nowadays many private universities, including Universitas Ma Chung, open a Study Program of Visual Communication Design. The Bachelor's program of Visual Communication Design of Universitas Ma Chung (henceforth DKV Ma Chung), which is based in Malang, is a considerably new study program and has not had a single graduate. The development of a study program in a private university highly depends on the number of its students. To get a high number of prospective students for the study program amidst the competition with those in other universities, DKV Ma Chung has to build a brand equity. Interactive multimedia is one that can fulfill the needs in delivering information more innovatively. Therefore, the purpose of this research is to design an interactive multimedia to introduce DKV Ma Chung as an effort to improve brand equity. The interactive multimedia designing uses the qualitative approach to design process termed ADDIE. ADDIE, which stands for includes Analysis, Design, Development, Implementation, and Evaluation, is a general design instructional model with a framework that helps media designing. The long-term benefit of this research is the increasing number of students of DKV Ma Chung, which is very important in the development of a study program.
\end{abstract}

Keywords: DKV Ma Chung, brand equity, ADDIE, and interactive multimedia 


\section{PENDAHULUAN}

Program studi Desain Komunikasi Visual (DKV) memiliki banyak peminat dan terus meningkat di setiap tahunnya. Di Malang Peminat program studi DKV dalam Seleksi Nasional Masuk Perguruan Tinggi Negeri (SNMPTN) meningkat signifikan dalam kurun waktu terakhir. Peminatnya mencapai 1.204 orang namun alokasi yang diterima hanya 21 orang (Surya, 2016). Semakin diminatinya program studi ini tidak lepas dari potensi karir lulusannya. Penyebab lainnya adalah zaman sekarang sudah banyak perguruan tinggi swasta yang membuka program studi DKV tidak terkecuali Universitas $\mathrm{Ma}$ Chung. Program studi S1 DKV Universitas Ma Chung atau lebih dikenal dengan DKV Ma Chung yang terletak di Malang ini merupakan program studi tergolong masih baru dan belum memiliki lulusan.

Program studi DKV Ma Chung hadir diantara persaingan ketat dengan program studi DKV perguruan tinggi swasta lain seperti DKV STIKI dan DKV Binus Malang. Pengelola perguruan tinggi swasta harus bekerja sangat ekstra untuk memperebutkan lulusan SMA/SMK/MA yang berkualitas. Dalam hal ini, tidak berbeda dengan dunia industri, persaingan antar perguruan tinggi untuk menarik calon mahasiswa juga sangat bergantung pada kekuatan merek masing-masing perguruan tinggi, terlepas dari kualitas pengelolaan perguruan tinggi maupun output lulusannya. Perkembangan suatu program studi di perguruan tinggi swasta sangat bergantung pada jumlah mahasiswa. Untuk memiliki peminat mahasiswa yang tinggi diantara peguruan tinggi swasta lain, program studi DKV Ma Chung harus memiliki brand equity.

Brand equity atau ekuitas merek dalam hal ini DKV Ma Chung untuk memiliki efek pembeda khas, unik dan positif yang ditimbulkan oleh pengetahuan nama merek terhadap interpretasi konsumen atas produk atau jasa tersebut. Ekuitas dapat dilihat dari respon konsumen tentang komunikasi pemasaran yang dilakukan merek. Suatu merek dapat dikatakan memiliki ekuitas positif apabila konsumen merasa lebih baik menggunakan suatu produk dan tertarik pada cara produk tersebut dipasarkan (Surachman, 2008). Salah satu strategi yang telah diterapkan untuk membentuk efek diferensial positif konsumen DKV Ma Chung adalah melalui identitas visual, namun efek diferensial positif tidak hanya oleh sebuah logo, namun juga yang muncul pada setiap komponen perusahaan berupa elemen-elemen visual pendukung (Putera \& Swasty, 2017).

Sejauh ini strategi pemasaran yang dilakukan program studi DKV Ma Chung masih menggunakan media standar seperti website dan brosur. Hal inilah yang menjadi alasan perlunya Program studi DKV Ma Chung untuk memiliki sebuah media yang inovatif dan efektif dengan konten kreatif yang mengedepankan ekuitas merek agar mampu meningkatkan minat calon mahasiswa program studi DKV Ma Chung. Multimedia interaktif adalah sebuah media yang mampu memfasilitasi kebutuhan dalam penyampaian informasi yang lebih inovatif dan efektif karena mampu mengkombinasikan berbagai media seperti gambar, video, suara dan tulisan dalam satu tampilan. 
Maka dari itu tujuan perancangan ini adalah merancang multimedia interaktif pengenalan DKV Ma Chung sebagai upaya meningkatkan brand equity. Menurut Vaughan (2006) multimedia adalah kombinasi dari teks, foto, seni grafis, suara, animasi, dan elemen-elemen video yang dimanipulasi secara digital. Ketika kita mengizinkan pengguna akhir/pemirsa dari proyek multimedia mengontrol apa dan kapan elemen-elemen tersebut akan dikirimkan, multimedia tersebut bersifat interaktif sehingga disebut multimedia interaktif. Interaktivitas ini dapat disebut sebagai interface design atau human factor design. Interaktivitas dapat dibagi menjadi dua macam struktur, yakni struktur linear dan struktur non linear. Struktur linear menyediakan satu pilihan situasi saja kepada pengguna sedangkan struktur non linear terdiri dari berbagai macam pilihan kepada pengguna. Manfaat jangka panjang dari perancangan multimedia interaktif ini adalah meningkatkan jumlah mahasiswa program studi DKV Ma Chung yang sangat penting bagi perkembangan program studi untuk kedepannya.

\section{METODE PERANCANGAN}

Metode perancangan menggunakan pendekatan kualitatif proses desain ADDIE (Martin.dkk, 2013) meliputi Analysis, Design, Development, Implementation, and Evaluation. ADDIE adalah model instruksi desain umum dengan sebuah framework yang membantu perancangan media. Model ini bersifat dinamis, fleksibel dalam perancangan konten yang efektif. Kelebihan model ADDIE menyediakan roadmap untuk semua konten dalam desain proses.

Pada tahap analysis memaparkan analisis atribut brand equity. Kotler dan Keller (2006) mendefinisikan ekuitas merek sebagai sejumlah aset dan sebuah tanggung jawab yang berhubungan dengan merek, nama, dan simbol, yang menambah atau mengurangi nilai dari produk atau pelayanan bagi perusahaan atau pelanggan perusahaan. Untuk meningkatkan nilai brand equity salah satunya yaitu memanfaatkan atribut brand equity yaitu meliputi : atribut brand awareness, atribut brand association, atribut perceived quality, dan atribut other assets.

Pada tahap design mendeskripsikan konten media ke dalam bentuk roadmap yang kemudian dikembangkan ke dalam desain flowchart untuk menentukan konsep desain dan implementasi multimedia interaktif DKV Ma Chung. Dalam perancangan sebuah multimedia interaktif, ini sangat penting untuk menggambarkan sistem alur konten dari sebuah multimedia interaktif. Ini tidak hanya membantu designer untuk memiliki gambaran dari sebuah multimedia interaktif yang akan dirancang tetapi juga membantu programer dalam menyusun sistem informasi dari multimedia interaktif tersebut. Alur multimedia interaktif adalah media komunikasi utama antara konsep media dan implementasinya dalam proses perancangan multimedia interaktif. Ada beberapa metode yang berbeda dalam penggambaran alur multimedia interaktif. Thomson (2004) menjelaskan sebuah metode penggambaran alur yang sering digunakan yaitu metode flowchart. 
Pada tahap development dilakukan proses compile desain final aset dengan engine program multimedia interaktif dengan mengacu pada desain flowchart. Tahap selanjutnya adalah tahap implementation yaitu mengimplementasikan aplikasi tersebut untuk bisa diakses oleh user/audiens secara masal. Tahap terakhir evaluation dilaksanakan untuk mengetahui adanya ketidaksesuaian atau error yang terjadi pada aplikasi atau konten yang masih belum efektif dan maksimal dalam menyampaikan brand equity DKV Ma Chung.

\section{HASIL DAN PEMBAHASAN}

\subsection{Analysis}

Proses analisis DKV Ma Chung mengacu pada pendekatan atribut brand equity meliputi : Brand Awareness , Brand Association, Brand Loyality, Perceived Quality, Other Assets.

\section{a. Atribut Brand Awareness}

Aaker (1991) mendefinisikan brand awareness sebagai kemampuan dari pelanggan potensial untuk mengenali atau mengingat bahwa suatu merek termasuk ke dalam kategori tertentu. Brand awareness memberikan banyak value, antara lain: memberikan tempat bagi asosiasi terhadap merek; memperkenalkan merek; merupakan sinyal bagi keberadaan, komitmen, dan substansi merek; dan membantu memilih sekelompok merek untuk dipertimbangkan dengan serius.

DKV Ma Chung telah memiliki standar identitas yang menjadi ciri khas yang membedakan dengan DKV pada universitas lain. Standar tersebut dibukukan kedalam sebuah format khusus yaitu corporate identity system yang didalamnya memuat standar untuk logo, warna, tipografi, elemen lainnya, layout, penerapan identitas dan incorrect use.

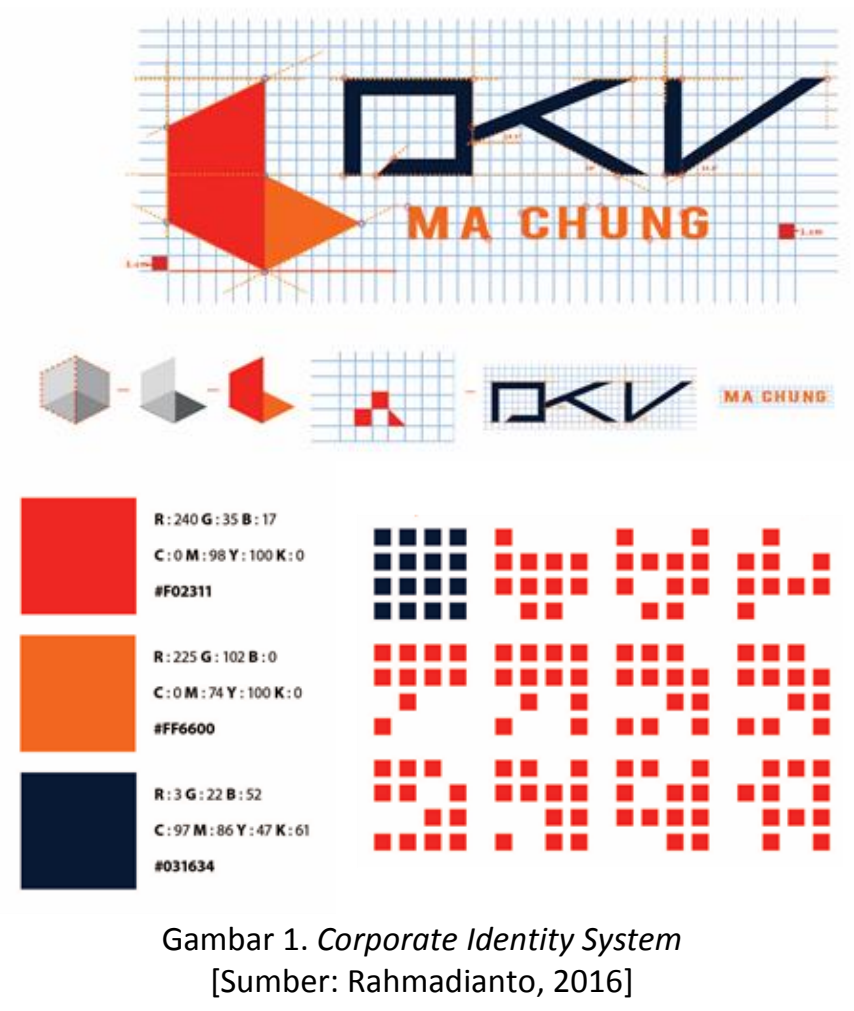




\section{b. Atribut Brand Association}

Aaker (1991) mendefinisikan brand association sebagai segala sesuatu yang terhubung di memori pelanggan terhadap suatu merek. Brand asscociation memberikan banyak value, antara lain: mempermudah pelanggan untuk mendapatkan informasi tentang merek; mempengaruhi interpretasi pelanggan atas fakta mengenai merek; membedakan merek dari merek pesaing; memperkuat posisi merek di pasar; alasan pelanggan untuk menggunakan merek; dasar untuk melakukan perluasan merek. Untuk menciptakan merek yang bernilai positif, maka ada beberapa yang dapat dilakukan seperti memanfaatkan atribut brand association meliputi: Product attributes; Intangibies; Customer benefits; Relative Price; Use / Application; User / Customer; Life Style / Personality; Product Class; Country / Geographic Area.

Brand association DKV Universitas Ma Chung dapat dioptimalkan melalui beberapa brand association yang dijelaskan sebagai berikut:

1) Product attributes: DKV Ma Chung di asosiasikan dengan konsentrasi penjurusan di desain media digital 2D dan 3D.

2) Intangibies : DKV Ma Chung di asosiasikan di asosiasikan memiliki semangat machung/budaya etnis Cina/12 nilai Ma Chung (rukun, bersatu, dan mengabdi)

3) Customer benefits : DKV Ma Chung di asosiasikan menghasilkan lulusan DKV yang unggul (kreatif, inovatif, berwawasan global berwirausaha) dan mampu terjun di dunia industri kreatif dengan estimasi masa tunggu kerja adalah 0 (nol).

4) Relative Price : DKV Ma Chung di asosiasikan dengan harga premium.

5) Use/Application : DKV Ma Chung di asosiasikan untuk pecinta desain/seni khususnya desain digital 2D dan 3D.

6) Use/Customer : DKV Ma Chung di asosiasikan dengan SMA/MA/SMK Tingkat akhir yang tertarik pada jurusan DKV.

7) Life Style/ Personality : DKV Ma Chung di asosiasikan dengan gaya hidup kreatif dan inovatif di dunia desain media digital.

8) Product Class : DKV Ma Chung di asosiasikan dengan program studi di perguruan tinggi swasta.

9) Country/Geographic Area : DKV Ma Chung di asosiasikan dengan program studi DKV di Malang.

\section{c. Atribut Brand Loyality}

Aaker (1991) mendefinisikan brand loyality sebagai ukuran ketertarikan pelanggan terhadap suatu merek. Tingkat ketertarikan pelanggan terhadap suatu merek dapat terbagi ke dalam empat tingkat, antara lain: switchers/price sensitive (pelanggan tidak loyal kepada merek atau belum memiliki brand equity yang kuat); satisfied/habitual buyer (pelanggan merasa puas terhadap produk atau setidaknya tidak merasa tidak puas terhadap produk perusahaan); satisfied buyer with switching cost (pelanggan merasa puas terhadap produk dan harus mengeluarkan biaya tertentu apabila ingin berpindah merek); dan sommitted buyer (Pelanggan memiliki rasa bangga menggunakan produk yang ditawarkan perusahaan. Mereka merekomendasikan merek yang sama kepada orang lain. Merek produk memiliki brand equity yang kuat di mata pelanggan). 
Ukuran DKV Ma Chung masih pada tahapan satisfied/habitual buyer pada tingkat ini, mahasiswa merasa puas terhadap DKV Ma Chung atau setidaknya tidak merasa tidak puas terhadap DKV Ma Chung. Mahasiswa juga sensitif terhadap benefit baru yang ditawarkan kepada mereka.

\section{d. Atribut Perceived Quality}

Aaker (1991) mendefinisikan perceived quality sebagai persepsi pelanggan terhadap kualitas atau keunggulan suatu produk atau jasa sehubungan dengan tujuan yang diinginkannya, dibandingkan dengan alternatif-alternatif lain. Jika persepsi pelanggan terhadap kualitas keseluruhan jelek, sebesar apapun usaha perusahaan untuk menciptakan loyalitas terhadap produk cenderung tidak akan berhasil..

Kualitas presepsi masyarakat terhadap DKV Ma Chung adalah positif hal ini menjadikan DKV Ma Chung merupakan salah satu program studi unggulan di Universitas $\mathrm{Ma}$ Chung.

\section{e. Atribut Other Assets}

Other asset DKV Ma Chung memiliki bagian-bagian sebagai berikut:

1) Keunggulan bersaing.

DKV Ma Chung memiliki sumber daya dosen dan fasilitas yang cukup baik dan memiliki kekhasan dalam penjurusan minat mahasiswa yaitu keolah desain media digital 2D dan 3D dan menjadi yang pertama di Malang;

2) Merek

DKV Ma Chung merupakan aset merek program studi DKV Ma chung yang membantu menambah nilai dan equity brand.

\subsection{Design}

Pada tahap design diawali dengan mendeskripsikan konten media kedalam bentuk roadmap. Roadmap digunakan sebagai konsep awal perancangan konten dalam media yang berisi kata kunci.

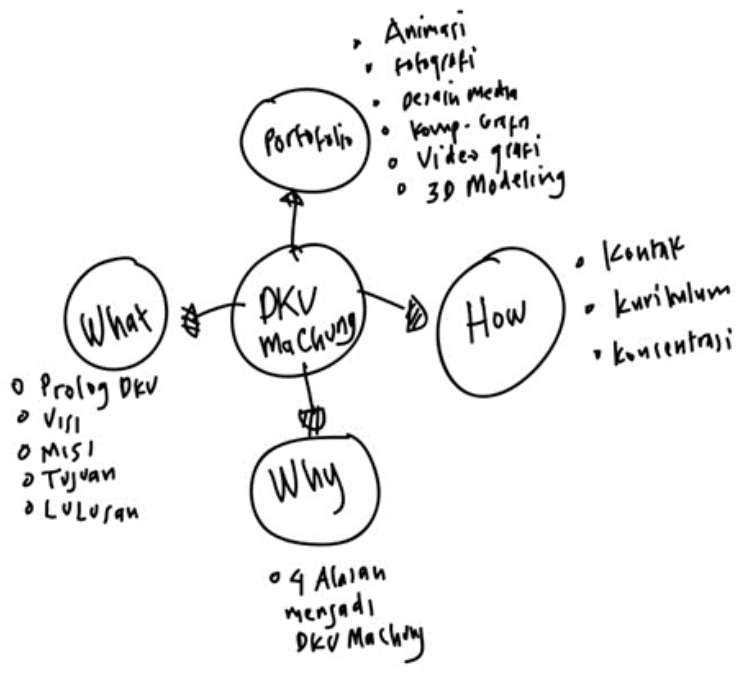

Gambar 2. Roadmap DKV Ma Chung

[Sumber: penulis] 
Semua konten yang akan dikomunikasikan dipilih berdasarkan pendekatan brand equity sehingga informasi yang disampaikan diharapkan mampu membentuk persepsi positif dan memperkuat brand equity dari DKV Ma Chung. Dari penjabaran roadmap kemudian dikembangkan ke dalam desain flowchart untuk menentukan konsep desain dan implementasi multimedia interaktif DKV Ma Chung.

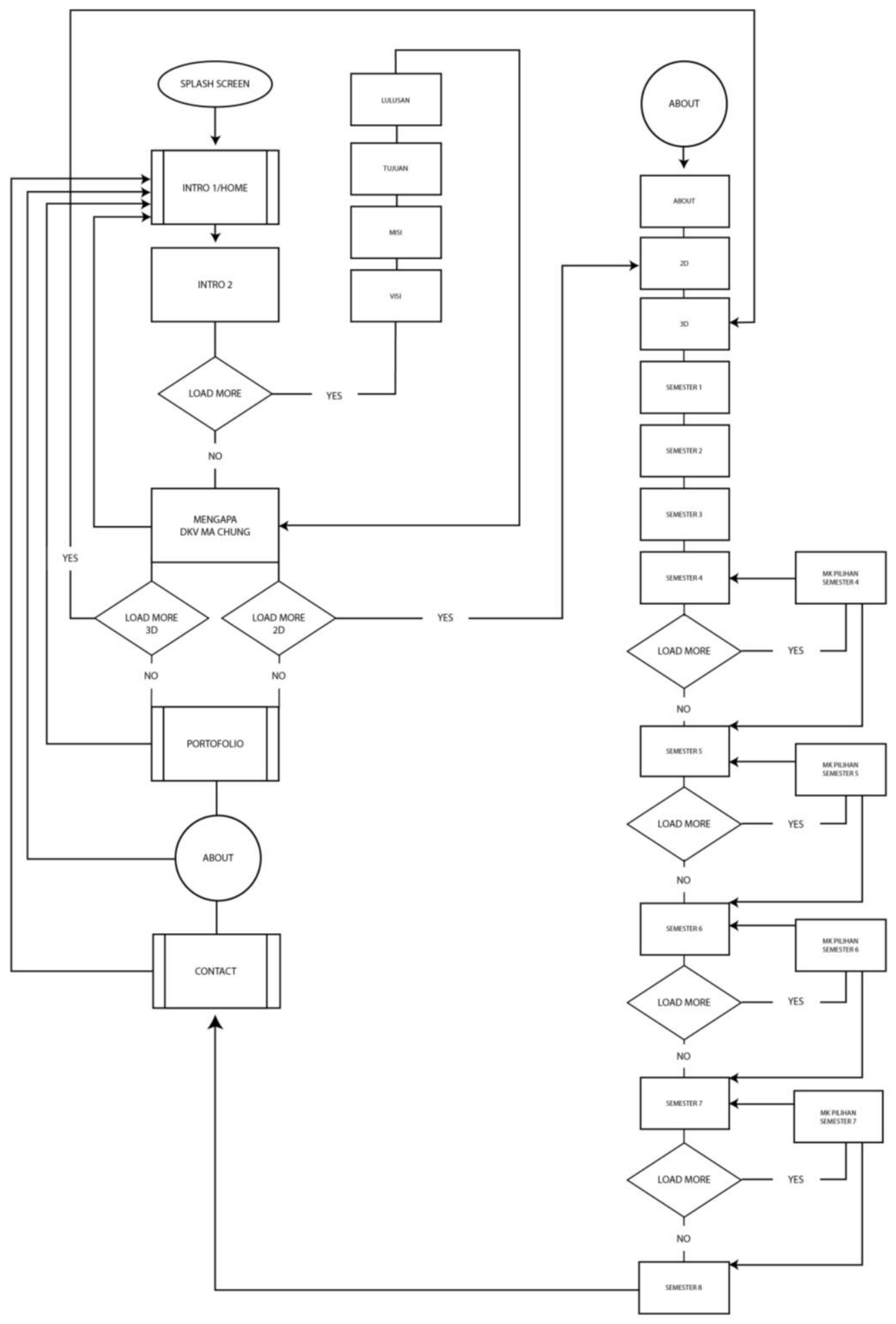

Gambar 3. Flowchart DKV Ma Chung

[Sumber: penulis] 
Konsep yang digunakan dalam penentuan urutan dan sistem flowchart pada konten adalah berdasarkan tingkat prioritas yang mampu meningkat brand equity DKV Ma Chung. Setelah desain flowchart membuat storyboard, digunakan sebagai panduan tata letak dari semua elemen multimedia interaktif pada setiap tampilan tatap muka. Storyboard ditampilkan dalam bentuk desain thumbnail. Desain tersebut merupakan varian style dari setiap tampilan tatap muka yang digunakan dalam menyampaikan konten.

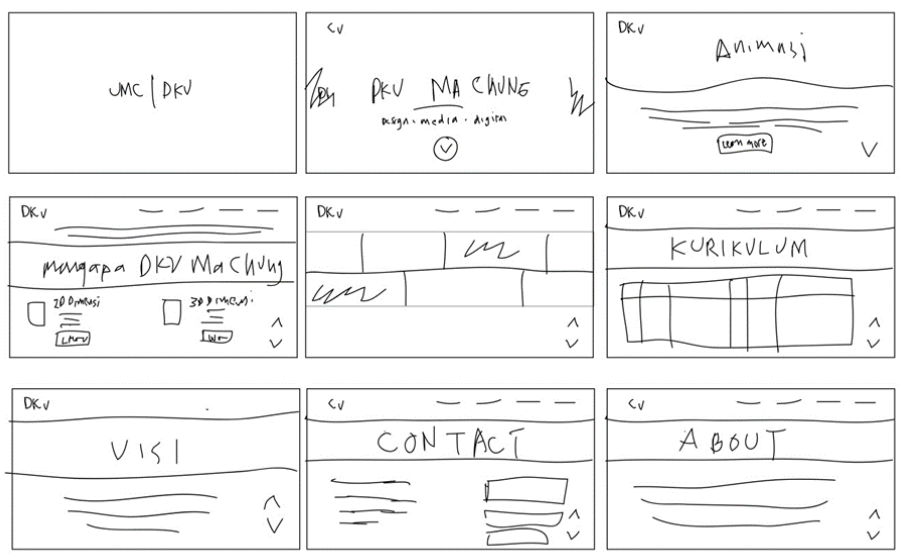

Gambar 4. Storyboard DKV Ma Chung

[Sumber: penulis]

Selanjutnya adalah proses finalisasi desain aset menggunakan teknik komputer. Desain aset ini bersifat final secara tampilan dan secara isi konten yaitu dengan pendekatan brand equity. Berikut hasil desain final aset pada tampilan utama :

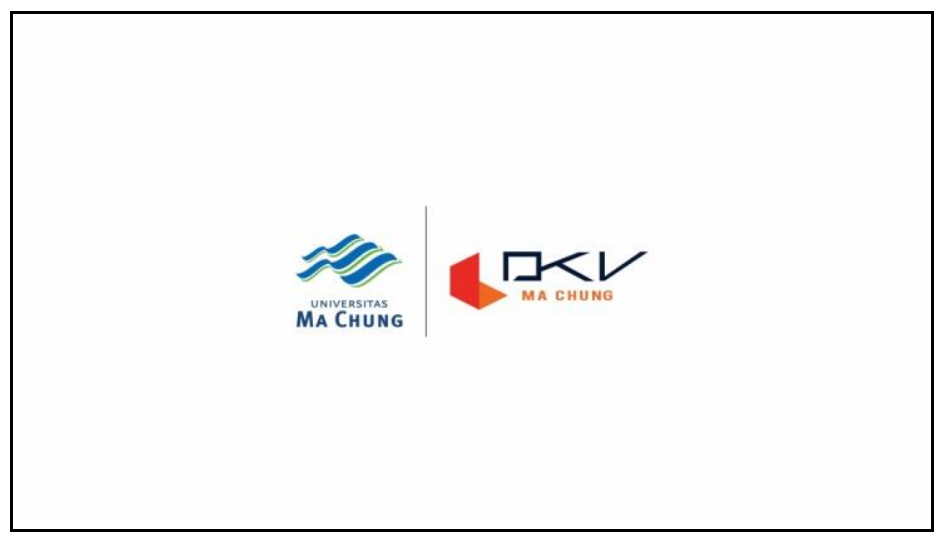

Gambar 5. Splashscreen DKV Ma Chung

[Sumber: penulis]

Tampilan gambar di atas merupakan desain aset splashscreen, pemilihan konten logo Universitas Ma Chung dan logo DKV Ma Chung bertujuan untuk memperkenalkan identitas DKV Ma Chung kepada audien dan menunjukkan identitas ini akan digunakan disetiap tampilan secara konsisten. Strategi penerapan atribut brand awareness dapat meningkatkan brand equity dari DKV MaChung. 


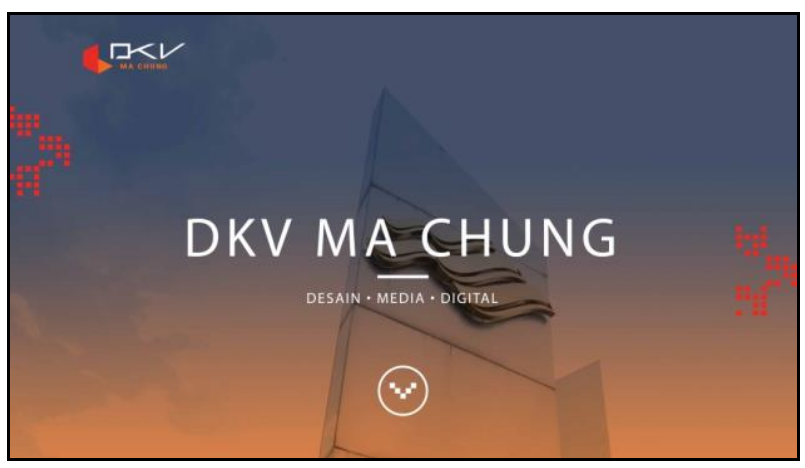

Gambar 6. Intro1 Multimedia Interaktif DKV Ma Chung [Sumber: penulis]

Tampilan gambar di atas merupakan desain aset tampilan intro1. Strategi penerapan atribut brand awareness melalui elemen bentuk khas DKV Ma Chung, logo DKV Ma Chung dan teks verbal "desain media digital" yang merupakan kata kunci pembeda yang membedakan dengan prodi DKV Ma Chung dengan prodi DKV lainnya.

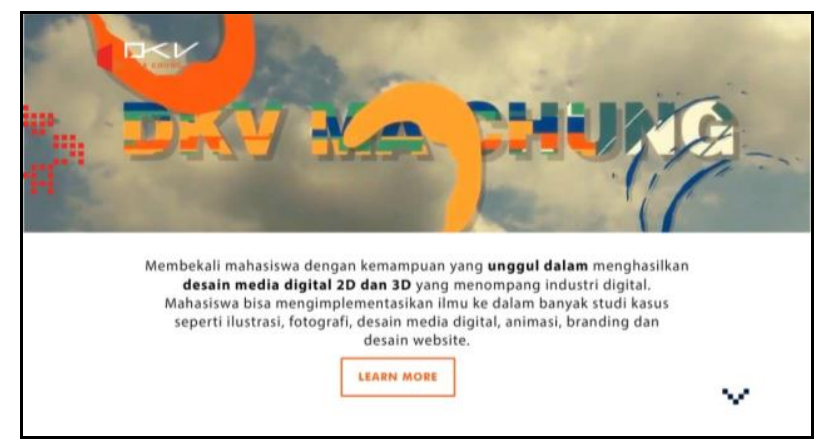

Gambar 7. Intro2 Multimedia Interaktif DKV Ma Chung [Sumber: penulis]

Tampilan gambar di atas merupakan desain aset tampilan intro2. Strategi tampilan memaksimalkan karakteristik DKV Ma Chung yaitu memiliki konsentrasi pada desain media digital melalui tampilan animasi tipografi kata DKV Ma Chung dan penerapan style huruf bold untuk penekan pada deskripsi kalimat pengantar DKV Ma Chung.

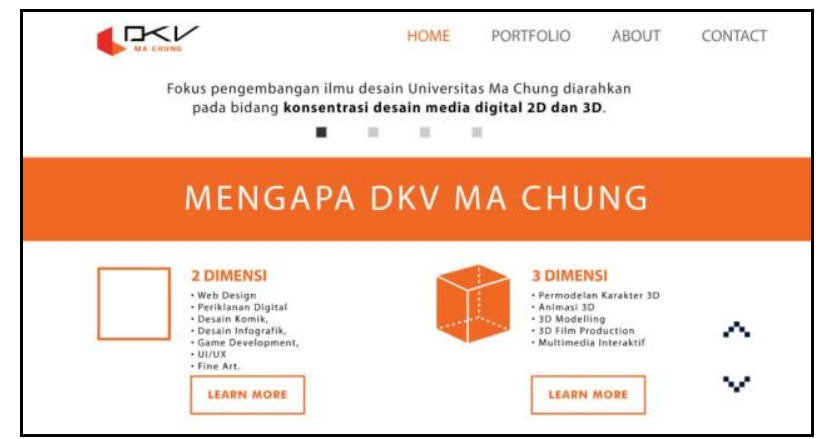

Gambar 8. Mengapa DKV Ma Chung Multimedia Interaktif DKV Ma Chung [Sumber: penulis] 
Tampilan gambar di atas merupakan desain aset tampilan mengapa DKV Ma Chung. Strategi memaksimalkan informasi atribut brand association seperti fokus konsentrasi desain media digital 2D dan 3D, penguasaan bahasa mandarin, kolaborasi lintas prodi melalui co-working space MDC, penerapan prinsip 12 nilai MA Chung.

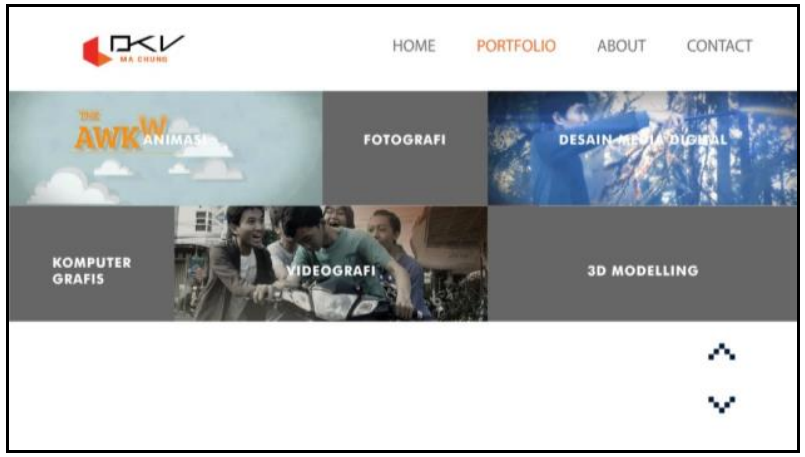

Gambar 9. Portofolio DKV Ma Chung Multimedia Interaktif DKV Ma Chung [Sumber: penulis]

Tampilan gambar di atas merupakan desain aset tampilan portofolio. Strategi tampilan memaksimalkan identitas atribut brand awareness melalui karya desain DKV yang telah dibuat oleh mahasiswa DKV Ma Chung seperti animasi, fotografi, desain media digital, komputer grafis, dan videografi, 3D modeling.

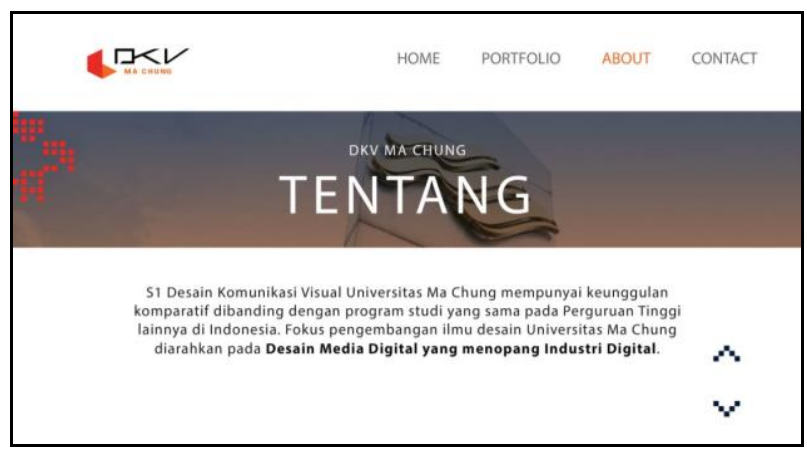

Gambar 10. About DKV Ma Chung Multimedia Interaktif DKV Ma Chung [Sumber: penulis]

Tampilan gambar di atas merupakan desain aset tampilan about. Strategi tampilan memaksimalkan identitas atribut brand awareness dan informasi konten ke arah atribut brand association seperti profil DKV Ma Chung, konsentrasi/penjurusan prodi DKV ke arah 2D dan 3D dan kurikulum prodi DKV. 


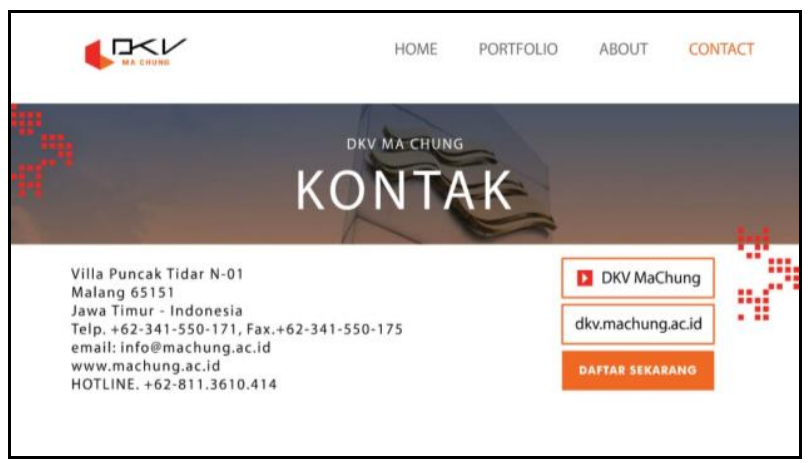

Gambar 11. Contact DKV Ma Chung Multimedia Interaktif DKV Ma Chung

[Sumber: penulis]

Tampilan gambar di atas merupakan desain aset tampilan contact. Strategi tampilan dari desain tatap muka adalah memaksimalkan identitas atribut brand awareness dan informasi konten ke arah atribut brand association, atribut perceived quality, atribut other assets seperti pemanfaatan sumber informasi tambahan seperti chanel youtube DKV Ma Chung dan website DKV Ma Chung untuk membentuk persepsi positif sehingga brand equity dari DKV Ma Chung semakin kuat.

\subsection{Development}

Tahap ini merupakan proses compile desain final aset dengan engine program multimedia interaktif dengan mengacu pada desain flowchart. Proses development ini menghasilkan sebuah desain berbentuk aplikasi berbasis android yang memungkinkan audiens/user bisa mengakses informasi tentang DKV Ma Chung secara interaktif.

\subsection{Implementation}

Setelah tahap compile desain final aset selesai proses selanjutnya adalah mengimplementasikan aplikasi tersebut untuk bisa diakses oleh user/audiens secara masal. Aplikasi ini telah diuji cobakan ke beberapa user dari berbagai latar belakang yaitu pelajar, mahasiswa, guru, dosen, dan masyarakat umum. Total jumlah user yang dijadikan sebagai sampel uji coba adalah sebanyak 10 orang. Waktu pelaksanaan uji coba bersifat flexible atau menyesuaikan kelonggaran waktu user yang dipilih. Metode dalam uji coba ini menggunakan teknik wawancara setelah user menggunakan aplikasi. Konten wawancara yang digunakan adalah merujuk dari seberapa besar kemampuan aplikasi ini dalam menyampaikan brand equity attribute DKV Ma Chung. Hasilnya secara garis besar aplikasi ini telah mampu sebagai medium komunikasi pengenalan DKV Ma Chung dan mampu menciptakan dampak positif terhadap persepsi masyarakat terhadap DKV Ma Chung.

\subsection{Evaluation}

Tahap evaluation merupakan serangkaian tahapan evaluasi media dari implementation yang telah dilaksanakan untuk mengetahui adanya ketidaksesuaian atau error yang terjadi pada aplikasi atau konten yang masih belum efektif dan maksimal dalam menyampaikan brand equity DKV Ma Chung. Metode yang digunakan dalam evaluasi ini merujuk dari hasil uji coba yang sudah dilaksanakan sebelumnya. Berdasarkan uji 
coba aplikasi dihasilkan beberapa evaluasi yang terbagi menjadi 2 bagian yaitu aspek teknis dan konten, untuk teknis terkait navigasi, dan sistem flow yang masih membuat bingung user sehingga ada beberapa konten yang terlewat sehingga konten brand equity tidak maksimal. Kemudian untuk isi konten ada beberapa tambahan yang diberikan untuk semakin meningkatkan brand equity.

\section{KESIMPULAN}

Program studi Desain Komunikasi Visual (DKV) memiliki banyak peminat dan terus meningkat disetiap tahunnya. Universitas Ma Chung adalah salah satu universitas swasta di Malang yang memiliki Program studi S1 DKV. Program Studi DKV Ma Chung di Universitas Ma Chung masih tergolong baru yaitu semenjak tahun 2015 dan masih belum banyak masyarakat yang mengetahui keberadaan program studi ini. Perkembangan suatu program studi di perguruan tinggi swasta sangat bergantung pada jumlah mahasiswa. Untuk memiliki peminat mahasiswa yang tinggi diantara peguruan tinggi swasta lain, program studi DKV Ma Chung harus memiliki brand equity.

Brand equity atau ekuitas merek dalam hal ini DKV Ma Chung untuk memiliki efek diferensial positif yang ditimbulkan oleh pengetahuan nama merek terhadap tanggapan konsumen atas produk atau jasa tersebut. Untuk meningkatkan nilai brand equity salah satunya yaitu memanfaatkan atribut brand equity yaitu meliputi brand awareness, brand association, perceived quality, dan other assets. Program studi DKV Ma Chung untuk memerlukan sebuah media yang inovatif dan efektif dengan konten kreatif yang mengedepankan ekuitas merek agar mampu meningkatkan minat calon mahasiswa program studi DKV Ma Chung. Multimedia interaktif adalah sebuah media yang mampu memfasilitasi kebutuhan dalam penyampaian informasi yang lebih inovatif dan efektif karena mampu mengkombinasikan berbagai media seperti gambar, video, suara dan tulisan dalam satu tampilan.

Metode perancangan multimedia interaktif menggunakan pendekatan kualitatif proses desain ADDIE (Martin.dkk, 2013) meliputi Analysis, Design, Development, Implementation, and Evaluation. Hasil dari penelitian ini adalah telah menghasilkan sebuah multimedia interaktif berbasis aplikasi android yang siap digunakan sebagai media pengenalan DKV Ma dengan konten isi dan visual merujuk dari pendekatan brand equity.

Saran untuk pengembangan penelitian selanjutnya adalah terbagi menjadi dua yaitu aspek teknis dan non teknis/konten media. Aspek teknis adalah mampu meningkatkan feature dan performance media agar semakin inovatif, efektif dan kreatif. Dan untuk aspek non teknis adalah mampu menggali data lebih dalam terkait brand equity DKV Ma Chung agar konten media semakin kuat dan memiliki presepsi positif dan meningkatkan brand equity. 


\section{DAFTAR PUSTAKA}

Aaker, A. David. 1991. Managing Brand Equity: Capitalizing on the value of a brand name. Free Press, New York.

Green, Timothy D. \& Brown, Abbie. 2002. Multimedia Projects in the Classroom: A Guide to Development and Evaluation. Corwin Press, UK.

Kotler, P \& Keller, K, L. 2006. Marketing Management. Prentice-Hall, Chicago.

Martin, Florence \& Hoskins, O. Jerome. Dkk. 2013. Development of an Interactive Multimedia Instructional Module. The Journal of Applied Instructional Design. VOL III.

Putera, D. Y., \& Swasty, W. 2017. Perancangan Identitas Visual dan Pengaplikasian pada Media Promosi Museum Sri Baduga. ANDHARUPA: Jurnal Desain Komunikasi Visual \& Multimedia, 3(02), 196-203.

Rahmadianto, Arif, Sultan. 2016. Perancangan Corporate Identity S1 Desain Komunikasi Visual Universitas Ma Chung sebagai Upaya Meningkatkan Brand Awareness. Jurnal Kreatif, Vol IV. STSRD VISI.

Surachman, SA. 2008. Dasar-Dasar Manajemen Merek: Alat Pemasaran untuk Memenangkan Persaingan. Bayumedia Publishing, Malang .

Surya. 2016. Desain Komunikasi Visual UM Banjir Peminat, Pendaftar Capai 1.204 Orang, yang Lolos hanya 21 Orang. http://suryamalang.tribunnews.com, diakses pada tanggal 19 Desember 2016.

Thomson. 2004. Game design for Teens. Premier. US.

Vaughan, Tay. 1993. Multimedia: Making It Work, Ninth Edition. McGrawHill, London. 